\title{
Bleeding from gastrointestinal ectopic varices is not associated with haemorrhage from oesophageal or gastric varices
}

\author{
Adriana Fabiola Romano-Munive, Félix Ignacio Tellez-Ávila \\ National Institute of Medical Sciences and Nutrition, Salvador Zubirán, Mexico
}

Gastroenterology Rev 2020; 15 (1): 60-64

DOI: https://doi.org/10.5114/pg.2020.93632

Key words: gastrointestinal haemorrhage, cirrhosis, portal hypertension, varices.

Address for correspondence: Adriana Fabiola Romano-Munive MD, MSc, National Institute of Medical Sciences and Nutrition, Salvador

Zubirán, Mexico, e-mail: fab_romanom@hotmail.com

\begin{abstract}
Introduction: Ectopic varices are those that appear in a different region of the gastroesophageal junction. Bleeding from ectopic varices is rare but is usually massive and deadly.

Aim: To identify the possible factors that cause bleeding from ectopic varices in patients with portal hypertension.

Material and methods: A cross-sectional and retrospective study; the data were collected between January 2004 and June 2014. We included patients with portal hypertension and gastrointestinal ectopic varices diagnosed by endoscopy.

Results: We found 31 patients with gastrointestinal ectopic varices. Of these, 25 had liver cirrhosis, and six showed non-cirrhotic portal hypertension. There were 16 men and 15 women in the study. The median age of the patients was 60 years (range minimum-maximum of 27 to 80 years). Nineteen (61\%) patients had rectal varices, 10 (32\%) had duodenal varices, 1 (3\%) had ileal varices, and $1(3 \%)$ had colonic varices. We found bleeding in $4(13 \%)$ of the 31 patients with ectopic varices; two belonged to the cirrhosis group, and the other two were from the non-cirrhotic portal hypertension group. Three of the 4 patients with bleeding from gastrointestinal ectopic varices had exhibited haemorrhage from oesophageal varices (odds ratio $=4.09,95 \% \mathrm{Cl}$ : $0.37-44.78, p=0.249$ ), but none of them showed bleeding from gastric varices.

Conclusions: Bleeding from gastrointestinal ectopic varices is not necessarily associated with bleeding from oesophageal or gastric varices.
\end{abstract}

\section{Introduction}

Ectopic varices (EV) are dilated portosystemic collateral veins that appear in a different region of the gastroesophageal junction, and they account for $2 \%$ to $5 \%$ of all variceal bleeding [1-3]. EV have a four-fold augmented risk of bleeding in comparison with oesophageal varices, and they can have a mortality rate of $40 \%$ $[4,5]$. EV may develop secondary to portal hypertension, abdominal surgery, abnormality in venous outflow, abdominal vascular thrombosis, hepatocellular carcinoma, or can be hereditary [6]. They have been localised in the duodenum, jejunum, ileum, colon, rectum, right diaphragm, bare area of the liver, biliary tree, splenic ligament, peritoneum, urinary bladder, umbilicus, peristomal skin, vagina, ovary, and testis [5]. They could be considered in persons with known hepatic disease or portal hypertension, and gastrointestinal bleeding when upper and lower endoscopies cannot identify a source of bleeding. The management of EV rupture includes pharmacotherapy, endoscopy, angiography, and surgery in selected cases [5].

EV present a clinical challenge because the aetiology is multiple, presentation is variable, diagnosis is heterogeneous, and management is not clear [1]. Current literature is restricted to case reports and series because of the infrequency of these lesions. There is scarce information on the clinical features of EV, and the factors associated with bleeding from this type of varix are unknown $[1,2,5]$.

\section{Aim}

The aim of this study is to identify the possible factors that cause bleeding from EV in patients with portal hypertension. 


\section{Material and methods \\ Patient characteristics}

This study had a cross-sectional and retrospective design and was performed at a reference centre. It was approved by the ethical review board of the National Institute of Medical Sciences and Nutrition Salvador Zubirán (REF. 2047). Informed consent was not required because it was a retrospective study. The sample included patients who had undergone upper endoscopy, colonoscopy, or enteroscopy during the period from January 2004 to June 2014. The eligibility criteria included patients older than 18 years, with portal hypertension and EV diagnosed by endoscopy. The sources of participant selection were electronic and paper medical records. The following information was collected for each patient: demographic characteristics, aetiology of cirrhosis or portal hypertension, Child-Pugh class, MELD score, localisation and bleeding from EV, history of bleeding from oesophageal or gastric varices, and diagnosis of portal gastropathy.

\section{Definitions}

Cirrhosis was diagnosed by compatible findings on clinical signs and symptoms, laboratory abnormalities, and imaging studies (increase in size of the left lobe of the liver, nodular liver, splenomegaly, ascites, development of collateral vessels or patent paraumbilical vessels) or liver biopsy. The Child-Pugh score was used to assess the liver disease severity. A diagnosis of portal hypertension was made with clinical manifestations (abdominal wall collateral vessels, splenomegaly, and thrombocytopaenia) or its complications (variceal haemorrhage, portal hypertensive gastropathy, or ascites) and compatible image findings. The diagnosis of non-cirrhotic portal hypertension was established based on the presence of portal hypertension, exclusion of cirrhosis, and diagnosis of another disorder that may cause it $[4,5,7]$.

Gastrointestinal bleeding was defined as the presence of haematemesis, coffee ground vomitus, melena, or haematochezia. EV was defined as variceal veins localised outside the oesophagus and proximal stomach in a patient with portal hypertension, and it was diagnosed on endoscopy as dilated submucosal veins dark blue in colour [5].

Upper endoscopy, colonoscopy, and double-balloon enteroscopy were performed under conscious sedation by an anaesthesiologist, with constant monitoring of vital signs, oxygen saturation, and electrocardiogram tracing, supplemental oxygen was used. The studies were done using conventional equipment (GIF 160-180 and CF 160-180L, Olympus, Tokyo, Japan).
A trained endoscopist, who had overcome the learning curve, performed all procedures. Standard colon preparation with polyethylene glycol 3350 (Nulytely, Asofarma) was utilised; during colonoscopy, the colonoscope was introduced until the cecum was recognised by the appendicular orifice, ileocecal valve, and tapeworm colonic junction. In the course of withdrawal, all segments were evaluated in a period of no less than 6 min.

Rectal varices were described as dilated veins reaching more than $4 \mathrm{~cm}$ over the anal verge, without prolapse on rectal examination; while a diagnosis of haemorrhoids was made with purple and dilated veins that did not prolong more than $4 \mathrm{~cm}$ over the dentate line, and frequently prolapse on rectal examination [5].

\section{Statistical analysis}

Data are expressed as medians and range minimum-maximum or proportions. There were no missing data. Univariate analysis was performed. Evaluation of data was carried out using Statistical Package for the Social Sciences (SPSS, version 20.0, Chicago, Illinois, USA). A $p$-value of $<0.05$ was considered statistically significant.

\section{Results}

During this period, we evaluated 37,923 upper endoscopies, 15,764 colonoscopies, and 648 double-balloon enteroscopies. We found 31 patients with EV, 25 with liver cirrhosis, and 6 with non-cirrhotic portal hypertension. Of this total, 16 (51.6\%) were men and 15 (48.3\%) were women, with a median age of 60 years (range minimum-maximum of 27 to 80 years). The most frequent aetiology of cirrhosis was alcoholic $6 / 25$ (24\%). Nine (36\%) patients were classified with Child-Pugh class A, 9 (36\%) with Child-Pugh class B, and 7 (28\%) with Child-Pugh class C; they showed a median MELD score of 13 (range minimum-maximum of 6 to 30). A median of three (range minimum-maximum of 0 to 15 ) years had passed between the diagnosis of liver cirrhosis and the detection of EV. The most frequent aetiology of non-cirrhotic portal hypertension was portal vein thrombosis $4 / 6$ (66.6\%). Of the total, 28 (90.3\%) patients had an upper endoscopy, 25 (80.6\%) patients had a colonoscopy, and only 3 patients had a double-balloon enteroscopy. We detected oesophageal varices in $28 / 31$ (90.3\%) patients, bleeding from oesophageal varices in 14/31 (45.1\%), gastric varices in $6 / 31$ (19.3\%), bleeding from gastric varices in $2 / 31$ (6.4\%), type 1 gastroesophageal varices (GOV 1) in $1 / 6$ (16.6\%), type 2 gastroesophageal varices (GOV 2 ) in $4 / 6$, and type 1 isolated gastric varices (IGV 1 ) in $1 / 6$ (16.6\%). Eighteen (58\%) patients had prophylaxis with 
Table I. Underlying pathologies in patients with ectopic varices

\begin{tabular}{ll} 
Pathology & Cases $(n)$ \\
\hline Cirrhosis: & 6 \\
\hline Alcohol & 5 \\
\hline Cryptogenic & 4 \\
\hline Primary biliary cirrhosis & 3 \\
\hline Hepatitis C virus infection & 2 \\
\hline Autoimmune hepatitis & 1 \\
\hline Overlap syndrome & 1 \\
\hline Primary sclerosing cholangitis & 1 \\
\hline Steatohepatitis & 1 \\
\hline Hepatitis B virus infection & 1 \\
\hline Polycystic liver disease & 25 \\
\hline Total & 4 \\
\hline Non-cirrhotic portal hypertension: & 6 \\
\hline Portal vein thrombosis & 2 \\
\hline Sotal & \\
\hline
\end{tabular}

$\beta$-blockers. Nineteen (61.2\%) patients had rectal varices, 10 (32.2\%) duodenal varices, 1 (3.2\%) ileal varices, and $1(3.2 \%)$ colonic varices (Table I).

\section{EV bleeding}

We found $4 / 31$ (12.9\%) cases of bleeding from EV: $2 / 25(8 \%)$ in the cirrhosis group and $2 / 6(33.3 \%)$ in the non-cirrhotic portal hypertension group, none of them had prophylaxis with $\beta$-blockers. Overall, two patients presented bleeding from duodenal varices: one from rectal varices and one from ileal varices. Two patients underwent a surgical procedure, and the other two received endoscopy treatment. Of these four patients, one was complicated with encephalopathy, and one died after presenting with hospital-acquired pneumonia, spontaneous bacterial peritonitis, and disseminated intravascular coagulation (Table II).

In the univariate analysis, bleeding from EV was not associated with bleeding from oesophageal varices (odds ratio $(\mathrm{OR})=4.09,95 \% \mathrm{Cl}: 0.37-44.78, p=0.24$ ) or gastric varices. Gender ( $\mathrm{OR}=3.75,95 \% \mathrm{Cl}: 0.34-40.8$, $p=0.27)$, cirrhosis $(\mathrm{OR}=0.17,95 \% \mathrm{Cl}: 0.01-1.61, p=$ $0.12)$, Child-Pugh class A (OR $=1.99,95 \% \mathrm{Cl}: 0.52-7.57$, $p=0.30)$, MELD score more than 20 points, duodenal location of $\mathrm{EV}(\mathrm{OR}=2.18, p=0.99)$, oesophageal varices $(\mathrm{OR}=0.25,95 \% \mathrm{Cl}: 0.01-3.66, p=0.31)$, gastric varices $(\mathrm{OR}=3.33,95 \% \mathrm{Cl}: 0.38-28.95, p=0.27)$, gastropathy $(\mathrm{OR}=0.71,95 \% \mathrm{Cl}: 0.06-8.39, p=0.78)$, and use of $\beta$-blockers were not associated with bleeding from EV.

\section{Discussion}

Our main results agree with those reported previously. We found 31 patients with EV, the sites of lesion included the rectum, duodenum, small intestine, and colon. The factors associated with EV bleeding are unknown, in the univariate analysis of the present study, EV bleeding was not associated with a history of haemorrhage from oesophageal or gastric varices (Figure 1).

The most common EV were rectal varices, observed in $19(61.2 \%)$ patients, followed by duodenal varices in $10(32.2 \%)$ cases, these findings were similar to those observed by the Clinical Research Committee of the Japan Society for Portal Hypertension [8] and Sato et al. [2], where the most frequent localisation was the rectum. The Japan Committee directed a national questionnaire survey to assess the situation of EV in Japan; 173 patients with EV were found, duodenal varices

Table II. Cases of bleeding from ectopic varices

\begin{tabular}{|c|c|c|c|c|c|c|c|c|}
\hline Sex & Age & $\begin{array}{c}\text { Portal } \\
\text { hypertension } \\
\text { aetiology }\end{array}$ & $\begin{array}{c}\text { Ectopic varices } \\
\text { location }\end{array}$ & Treatment & $\begin{array}{l}\text { Oesophageal } \\
\text { varices }\end{array}$ & $\begin{array}{l}\text { Bleeding from } \\
\text { oesophageal } \\
\text { varices }\end{array}$ & Gastric varices & $\begin{array}{l}\text { Bleeding from } \\
\text { gastric varices }\end{array}$ \\
\hline $\mathrm{F}$ & 70 & Cirrhosis & Rectum & $\begin{array}{l}\text { Rubber band } \\
\text { ligation }\end{array}$ & Yes & Yes & No & No \\
\hline $\mathrm{F}$ & 36 & Cirrhosis & Ileum & $\begin{array}{l}\text { Cyanoacrylate } \\
\text { injection }\end{array}$ & Yes & Yes & $\begin{array}{l}\text { Yes } \\
\text { GOV-2 }\end{array}$ & No \\
\hline M & 35 & $\begin{array}{c}\text { Portal } \\
\text { thrombosis }\end{array}$ & Duodenum & Duodenectomy & Yes & Yes & No & No \\
\hline $\mathrm{F}$ & 21 & $\begin{array}{c}\text { Portal } \\
\text { thrombosis }\end{array}$ & Duodenum & Sugiura & No & No & $\begin{array}{c}\text { Yes } \\
\text { IGV-1, IGV-2 }\end{array}$ & No \\
\hline
\end{tabular}

GOV-2 - type 2 gastroesophageal varices, IGV-1 - type 1 isolated gastric varices, IGV-2 - type 2 isolated gastric varices. 
were detected in 57 (33\%) cases, small intestinal varices in $11(6.3 \%)$ cases, colonic varices in $6(3.1 \%)$ cases, and rectal varices in $77(44.5 \%)$ cases [8]. While Sato et al. [2] reported that the frequency of EV was 43/1218 (3.5\%) in patients with portal hypertension, the locations of the EV were rectal in 32 patients, duodenal in three, intestinal in two, vesicular in three, stomal in one, and colonic in two [2]. On the other hand, Lebrec and Benhamou [9] reported EV at the jejunum or ileum in $18 \%$ of cases, duodenum in $17 \%$, colon in $14 \%$, rectum in $8 \%$, and peritoneum in $9 \%$ (Figure 2 ).

It has been observed that cases with rectal varices frequently had an antecedent of oesophageal varices (94.8\%) and required treatment by endoscopy (87\%) [8]. In this report, 29 of 31 patients had oesophageal varices $(93.5 \%)$; of the patients with rectal varices $(n=19)$, 16 (84.2\%) had oesophageal varices (85\%). Goenka et al. [10] demonstrated in a case-control study that patients with portal hypertension had more anorectal varices in comparison with those with cirrhosis and portal hypertension (89\% and 56\%, respectively), and rectal varices were identified more often in patients with portal vein thrombosis compared with those with cirrhosis or non-cirrhotic portal hypertension (80\%, 28\%, and $30 \%$, respectively) (Figure 3 ).

The selection of treatment is determined by the endoscopist's skills, site of the EV, and technical options [5]. The management of EV bleeding in the present study was performed by endoscopic treatment $2 / 4$ (50\%) and surgery 2/4 (50\%). The mortality associated with EV bleeding is undefined because of insufficient information but is influenced by the severity of liver disease [5]. In this report, there was $25 \%$ mortality.

The two main limitations of this investigation were that it originated from a retrospective study and the small sample size of EV. Bias may have altered the re-

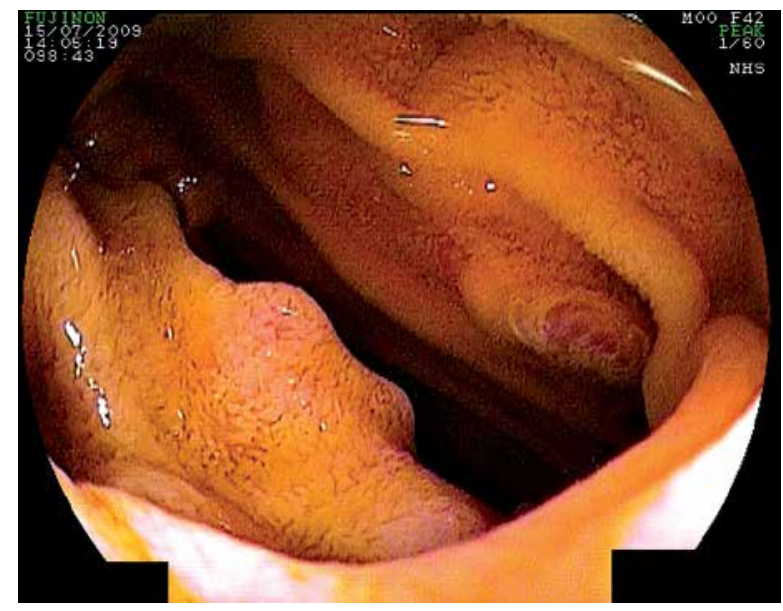

Figure 2. Upper endoscopy showing an ectopic varix in the duodenum

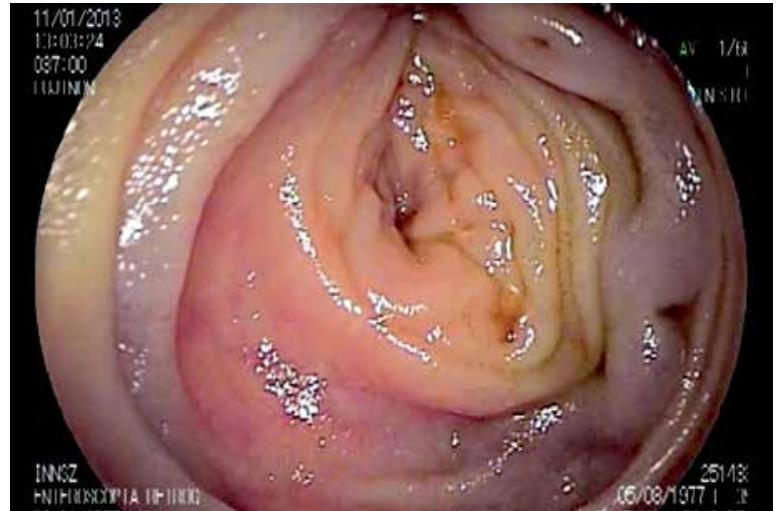

Figure 1. Retrograde double balloon enteroscopy showing an ectopic varix in the proximal ileum with a stigma of recent bleeding

sults, due to its retrospective design; in particular, the prevalence of EV may have been underestimated. The Clinical Research Committee of the Japan Society for Portal Hypertension [8] reported 173 cases, Li et al. [11] 64 cases, and Sato et al. [2] 43 cases; we reported 31 cases. The small sample in this study resulted in large confidence intervals in the estimates of risk factors of bleeding from EV (Table III). Failure to differentiate between rectal varices and haemorrhoids reported in the literature could be a source of potential imprecision in this report [12]. We did not show the frequency of EV in extraintestinal sites. However, this is the first study to investigate risk factors for bleeding from EV. This manuscript includes 10 years of data on a rare disease and, to our knowledge, is the report with the largest sample size in a Latin American population. These results can be generalised to other populations with portal hypertension. Studies with larger samples are needed to determine other potential factors that cause bleeding from EV.

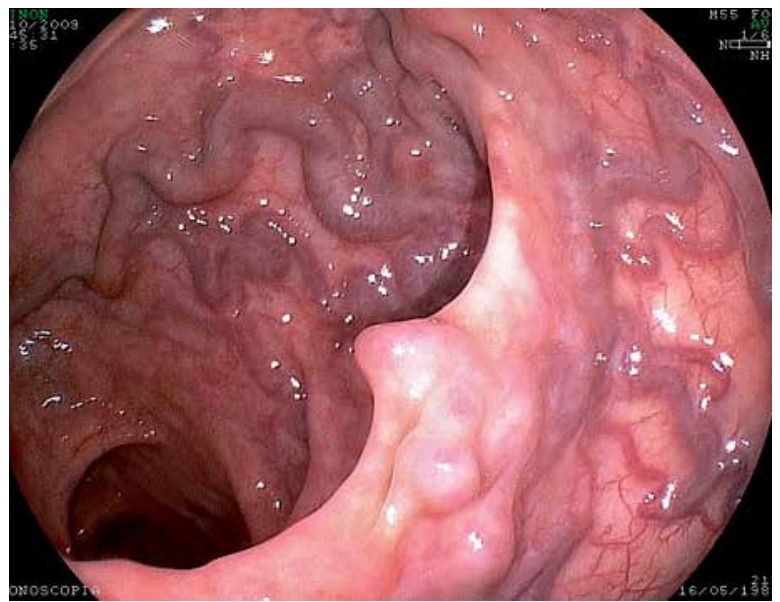

Figure 3. Colonoscopy showing an ectopic varix in the rectum 
Table III. Characteristics of ectopic varices studies

\begin{tabular}{|c|c|c|c|c|c|}
\hline Author, year & Ectopic varices $(n)$ & Treatment & Success (\%) & Recurrence (\%) & Mortality (\%) \\
\hline Watanabe, 2010 & 173 & $\begin{array}{c}\text { Observation } 41.1 \% \\
\text { Endoscopic } 29.2 \% \\
\text { Interventional radiology } 14.3 \% \\
\text { Combination } 6.1 \% \\
\text { Surgery } 7.7 \%\end{array}$ & 54.9 & 9.7 & 32.1 \\
\hline Li, 2013 & 64 & Endoscopic 54.6\% & NR & NR & NR \\
\hline Sato, 2011 & 43 & $\begin{array}{c}\text { Endoscopic } 74.4 \% \\
\text { Interventional radiology } 20.9 \% \\
\text { Combination } 4.6 \%\end{array}$ & NR & NR & NR \\
\hline Romano, 2016 & 31 & $\begin{array}{l}\text { Observation } 87 \% \\
\text { Endoscopic } 6.4 \% \\
\text { Surgery } 6.4 \%\end{array}$ & 100 & NR & 25 \\
\hline
\end{tabular}

\section{Conclusions}

Active bleeding from EV is not associated with a history of haemorrhage from oesophageal or gastric varices in patients with portal hypertension.

\section{Acknowledgments}

We acknowledge to the Academic Writing Team of the Centro de Estudios de Posgrado UNAM for their help with this manuscript.

\section{Conflict of interest}

The authors declare no conflict of interest.

\section{References}

1. Sharma B, Raina S, Sharma R. Bleeding ectopic varices as the first manifestation of portal hypertension. Case Reports Hepatol 2014; 2014: 140959.

2. Sato T, Akaike J, Toyota J, et al. Clinicopathological features and treatment of ectopic varices with portal hypertension. Int J Hepatol 2011; 2011: 960720.

3. Norton ID, Andrews JC, Kamath PS. Management of ectopic varices. Hepatology 1998; 28: 1154-8.

4. Saad WE, Lippert A, Saad NE, et al. Ectopic varices: anatomical classification, hemodynamic classification, and hemodynamic-based management. Tech Vasc Interv Radiol 2013; 16: 158-75.

5. Almadi MA, Almessabi A, Wong P, et al. Ectopic varices. Gastrointest Endosc 2011; 74: 380-8.

6. Helmy A, Al Kahtani K, Al Fadda M. Updates in the pathogenesis, diagnosis and management of ectopic varices. Hepatol Int 2008; 2: 322-34.

7. Henry Z, Uppal D, Saad W, et al. Gastric and ectopic varices. Clin Liver Dis 2014; 18: 371-88.

8. Watanabe N, Toyonaga A, Kojima S, et al. Current status of ectopic varices in Japan: results of a survey by the Japan Society for portal hypertension. Hepatol Res 2010; 40: 763-76.

9. Lebrec D, Benhamou JP. Ectopic varices in portal hypertension. Clin Gastroenterol 1985; 14: 105-21.
10. Goenka MK, Kochhar R, Nagi B, et al. Rectosigmoid varices and other mucosal changes in patients with portal hypertension. Am J Gastroenterol 1991; 86: 1185-9.

11. Li N, Liu YD, Yang YS, et al. A retrospective analysis of ectopic varices in gastrointestinal tract diagnosed by endoscopy. Zhonghua Nei Ke Za Zhi 2013; 52: 936-9.

12. Bini EJ, Lascarides CE, Micale PL, et al. Mucosal abnormalities of the colon in patients with portal hypertension: an endoscopic study. Gastrointest Endosc 2000; 52: 511-6.

Received: 5.12 .2018

Accepted: 27.05.2019 